\title{
Successful Percutaneous Mitral Valve Balloon Valvuloplasty during Third Trimester
}

\author{
${ }^{1}$ Mamatha Shivanagappa, ${ }^{2} \mathrm{G}$ Sindhu Sree, ${ }^{3}$ Priyankur Roy, ${ }^{4}$ Nandish Manoli
}

\begin{abstract}
Rheumatic mitral stenosis is the most common acquired valvular lesion in pregnant women. The overall mortality is $1 \%$, but can go up to $5 \%$ in those patients with New York Heart Association class III and IV symptoms. Percutaneous mitral balloon valvuloplasty (PMBV) is the procedure of choice in the treatment of rheumatic mitral stenosis. The PMBV is usually done in the first or second trimester, but in the third trimester, PMBV is a less common procedure.

A 24-year-old gravida 2 para 1 living 1 with 35 weeks of gestation with previous lower segment cesarean section (LSCS) presented with breathlessness and swelling of lower limbs. Evaluation revealed rheumatic mitral stenosis of moderate severity with moderate mitral regurgitation with cardiac failure. Hence, PMBV was done, which resulted in increase of mitral valve area from 0.6 to $1.7 \mathrm{~cm}^{2}$. She had marked symptomatic improvement, and cesarean section was done at 36 weeks 5 days for previous LSCS with preterm premature rupture of membranes. The postoperative period was uneventful.

Our report reinforces the fact that third trimester PMBV is safe and effective during pregnancy with no untoward effect on the fetus.
\end{abstract}

Keywords: Balloon valvuloplasty, Mitral stenosis, Pregnancy, Rheumatic heart disease.

How to cite this article: Shivanagappa M, Sree GS, Roy P, Manoli N. Successful Percutaneous Mitral Valve Balloon Valvuloplasty during Third Trimester. J South Asian Feder Obst Gynae 2017;9(2):182-184.

Source of support: Nil

Conflict of interest: None

Date of received: 31 January 2017

Date of acceptance: 21 March 2017

Date of publication: April 2017

\section{INTRODUCTION}

Rheumatic heart disease continues to be a major heart problem associated with pregnancy in India, though

${ }^{1}$ Assistant Professor, ${ }^{2,3}$ Postgraduate Student, ${ }^{4}$ Professor and Unit Chief

1-4 Department of Obstetrics and Gynecology, Jagadguru Sri Shivarathreeshwara University, Mysuru, Karnataka, India

Corresponding Author: Mamatha Shivanagappa, B-106, Brigade Solitaire Apartments, Alanahally Layout, Mysuru, Karnataka India, Phone: +919845047939, e-mail: mamathamahesh106@ gmail.com currently it shows a declining trend. ${ }^{1}$ Rheumatic mitral stenosis forms around $88 \%$ of the heart diseases complicating pregnancy in the tertiary referral centers in India, and it is also a frequent cause of maternal death. ${ }^{2}$ It is a progressive disease that leads to heart failure and is finally fatal unless mechanical intervention enlarges the mitral valve orifice to permit adequate cardiac output. Pregnant patients with critical mitral valve stenosis form a high-risk group, who are at significantly increased risk of life-threatening complications. The increased frequency of preterm delivery in mitral stenosis is well known.

Mitral balloon valvuloplasty (MBV), which is the procedure of choice for the treatment of mitral stenosis, has excellent immediate and long-term results. During pregnancy, the second trimester is the preferred period for this invasive procedure. The MBV is safe and effective during pregnancy with no untoward effect on the fetus. ${ }^{3}$ Our experience of a successful percutaneous mitral balloon valvuloplasty (PMBV) during the third trimester is reported herewith.

\section{CASE REPORT}

A 24-year-old lady, gravida 2 para 1 living 1 with 35 weeks of gestation, presented to the Department of Obstetrics and Gynecology, Jagadguru Sri Shivarathreeshwara Hospital (a tertiary care teaching hospital attached to Jagadguru Sri Shivarathreeshwara Medical College), Mysuru, India, with history of breathlessness and swelling of lower limbs since 15 days. Her previous child birth was by cesarean section done 5 years back due to nonprogress of labor, and her postoperative period and puerperium was uneventful. She did not have any other comorbidities, such as hypothyroidism, diabetes mellitus, and hypertension.

On examination, pulse rate was $104 \mathrm{bpm}$, blood pressure $150 / 100 \mathrm{~mm} \mathrm{Hg}$, respiratory rate $28 /$ minute, and hemoglobin saturation was $97 \%$ on room air. She had bilateral pitting pedal edema and the jugular venous pressure was raised. Examination of cardiovascular system revealed tachycardia and $S_{3}$ gallop; basal crepitation was present on respiratory system examination. Upon abdomen examination, uterus of 36 weeks size was palpable; fetus was in cephalic presentation, and fetal heart sound was 150/minute. Central nervous system examination showed no focal neurological deficit. 
Hematological and biochemical investigations, such as complete hemogram, renal function tests, liver function tests, and urinary investigations were normal. Fundoscopy showed bilateral early papillary edema. Echocardiogram showed rheumatic heart disease with moderate mitral stenosis and mitral regurgitation with mild aortic regurgitation and tricuspid regurgitation with moderate pulmonary arterial hypertension; ejection fraction was $55 \%$ and mild pericardial effusion was also present.

As per cardiology consultation and advice, she was started on Tab. Metaprolol $25 \mathrm{mg}$ and was planned for percutaneous trans-mitral commissurotomy. Percutaneous mitral balloon valvuloplasty was performed and she showed marked symptomatic improvement. On post-MBV day 7 , she had preterm premature rupture of membranes and was taken up for emergency cesarean section. She delivered a late preterm male baby weighing $2.4 \mathrm{~kg}$. She was shifted to the coronary care unit for close monitoring and was put on elective ventilation. She was extubated on postlower segment cesarean section day 2 . Her vitals were stable. The postoperative period was uneventful, and she was discharged on day 7.

\section{DISCUSSION}

Mitral stenosis prevents emptying of the left atrium and subsequent filling of the left ventricle, resulting in decreased stroke volume and decreased cardiac output. Consequent to the fixed cardiac output state, the heart cannot cope with situations warranting increased metabolic demand or increased blood volume. ${ }^{4}$ This increased volume load and tachycardia together cause the patients to deteriorate and advance from one New York Heart Association (NYHA) class to another. The major risks during pregnancy are atrial fibrillation, embolic events, and pulmonary edema. ${ }^{5}$

Without intervention, the maternal mortality for patients with severe mitral stenosis, who are in NYHA class I and II, is 0 to $4 \%$ and is significantly higher at 6 to $8 \%$ for those in NYHA class III and IV. When the normal mitral valve orifice area of 4 to $6 \mathrm{~cm}^{2}$ is progressively reduced to $2 \mathrm{~cm}^{2}$, the classical symptoms of mitral heart disease start appearing. ${ }^{6}$ Cardiac decompensation and pulmonary edema may occur in pregnant women with overt or silent mitral valve stenosis during the second or third trimester (Fig. 1). ${ }^{7}$

The PMBV has been performed on pregnant patients and is reported to be a safe and effective treatment to improve the mother's hemodynamic status, and it is well tolerated by the fetus. ${ }^{8}$ Only those patients with Wilkins score of $<8$ have to be subjected to the procedure. The Wilkins score is a scoring system based on valvular mobility, calcification, and thickening, as well as subvalvular thickening as seen on an echocardiogram. The possible scores range from 4 to 16. The lower the score, the more favorable is the valvular anatomy for those undergoing PMBV. ${ }^{9}$

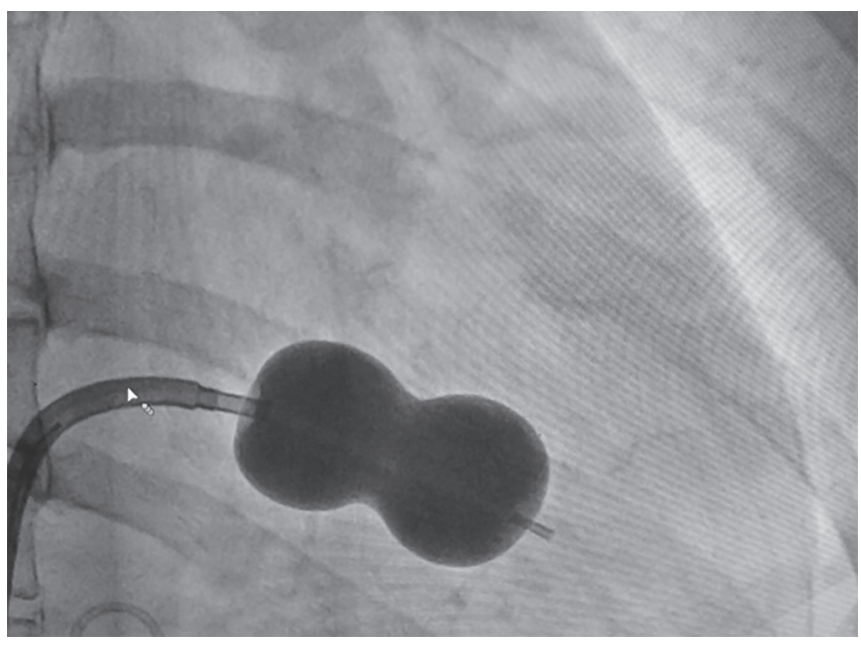

Fig. 1: The PMBV being performed

Echocardiography is the standard imaging tool used to assess patients with mitral stenosis, and it provides information regarding the area of the mitral valve, size of the left atrium, presence of thrombus, and the size and function of the left ventricle and right-sided chambers. Doppler examination provides information about the severity of the stenosis, the presence of other associated valve lesions, and the degree of pulmonary hypertension. ${ }^{10}$ The greatest risk occurs in the peripartum period, and the most deaths occur between the second and ninth days postpartum.

Pregnant patients with critical mitral valve stenosis form a high-risk group who are at significantly increased risk of life-threatening complications. Despite improvements in medical treatment, mitral stenosis in pregnancy remains a dangerous condition for the mother and fetus. A better understanding of the physiological changes in pregnancy and the pathological impact of mitral stenosis over pregnancy and a multidisciplinary approach in diagnosis and management reduce the mortality and morbidity. Women who remain symptomatic and have moderate-to-severe mitral stenosis require surgical treatment. The PMBV provides palliation for pregnant women with mitral stenosis. ${ }^{11}$

\section{CONCLUSION}

Our experience of a successful PMBV during the third trimester reinforces the fact that PMBV is safe and effective during pregnancy with no untoward effect on the fetus.

\section{ACKNOWLEDGMENT}

Author would like to thank Dr Nagaraj Desai, Professor and Head, Department of Cardiology, Jagadguru Sri Shivarathreeshwara Medical College \& Hospital, Mysuru, and Dr H Basavana Gowdappa, Dean, Faculty of Medicine and Professor, Department of Medicine, Jagadguru Sri Shivarathreeshwara Medical College \& Hospital, Mysuru. 


\section{REFERENCES}

1. Ben Farhat M, Ayari M, Maatouk F, Betbout F, Gamra H, Jarra M, Tiss M, Hammami S, Thaalbi R, Addad F. Percutaneous balloon versus surgical closed and open mitral commissurotomy: seven-year follow-up results of a randomized trial. Circulation 1998 Jan;97(3):245-250.

2. Agarwal BL. Rheumatic heart disease unabated in developing countries. Lancet 1981 Oct;2(8252):910-911.

3. Pavankumar P, Venugopal P, Kaul U, Iyer KS, Das B, Sampathkumar A, Airon B, Rao IM, Sharma ML, Bhatia ML, et al. Closed mitral valvotomy during pregnancy. A 20-year experience. Scand J Thorac Cardiovasc Surg 1988;22(1):11-15.

4. Goon MS, Raman S, Sinnathuray TA. Closed mitral valvotomy in pregnancy - a Malaysian experience. Aust N Z J Obstet Gynaecol 1987 Aug;27(3):173-177.

5. Pomini F, Mercogliano D, Cavalletti C, Caruso A, Pomini P. Cardiopulmonary bypass in pregnancy. Ann Thorac Surg 1996 Jan;61(1):259-268.

6. Mangione JA, Zuliani MF, Del Castillo JM, Nogueira EA, Arie S. Percutaneous double balloon mitral valvuloplasty in pregnant women. Am J Cardiol 1989 Jul;64(1):99-102.
7. Esteves CA, Ramos AI, Braga SL, Harrison JK, Sousa JE. Effectiveness of percutaneous balloon mitral valvotomy during pregnancy. Am J Cardiol 1991 Oct;68(9):930-934.

8. Iung B, Cormier B, Elias J, Michel PL, Nallet O, Porte JM, Sananes S, Uzan S, Vahanian A, Acar J. Usefulness of percutaneous balloon commissurotomy for mitral stenosis during pregnancy. Am J Cardiol 1994 Feb:73(5):398-400.

9. Ben Farhat M, Maatouk F, Betbout F, Ayari M, Brahim H, Souissi M, Sghairi K, Gamra H. Percutaneous balloon mitral valvuloplasty in eight pregnant women with severe mitral stenosis. Eur Heart J 1992 Dec;13(12):1658-1664.

10. Brigui M, Remadi F, Belkhiria N, Ata J, Chebrak S, Marmouri M, Handous A. Results of percutaneous mitral dilatation in 11 cases of poorly tolerated mitral stenosis during pregnancy. Ann Cardiol Angeiol (Paris) 1994 Mar;43(3): 129-134.

11. Wilkins GT, Weyman AE, Abascal VM, Block PC, Palacios IF. Percutaneous balloon dilatation of the mitral valve: an analysis of echocardiographic variables related to outcome and the mechanism of dilatation. Br Heart J 1988 Oct;60(4): 299-308. 